\title{
Combining Statistical and Interpretative Analyses for Testing Readiness and IT Adoption Questionnaire
}

\author{
Asrul Sani ${ }^{1,2}$, T K A Rahman ${ }^{2}$, Aang Subiyakto², Ninuk Wiliani ${ }^{2,4}$ \\ ${ }^{1}$ Departement of Information Systems, STMIK Widuri, Jakarta, Indonesia \\ ${ }^{2}$ Departement of ICT, Asia e University, Kuala Lumpur Malaysia \\ ${ }^{3}$ Departement of Information Systems, Syarif Hidayatullah State Islamic University, Indonesia \\ ${ }^{4}$ Departement of ICT, National of Science and Technology Institut, Jakarta, Indonesia
}

E-mail: asrulsani@kampuswiduri.ac.id

\begin{abstract}
A questionnaire is one method that is very widely used for social research and is an essential stage in an information system survey in this case the instrument adopted from previous research. Research in the field of information systems today is highly developed by the context ranging from industry, education, and other areas that are not limited. The objectives of this study were to assess the nature of the psychometric properties of users, in this case, is the level of readiness of users in adopting information technology in SMEs. Respondents were chosen randomly and were active computer users in SMEs, and the questions and statements given could be responded to and understood well so that the perceptions between researchers and respondents were the same. The population used is by taking several SMEs industries in Jakarta. The survey was conducted by interviewing and distributing questionnaires to employees at SMEs. Data processing is done using partial least squares structural equation modeling (PLS-SEM). The results obtained are 13 of the 70 questions were recommended to be rejected. Besides, the findings can be used by other parties in terms of testing a questionnaire as a reference for consideration, and the confirmation results can be used as a reference in revising the questionnaire questions.
\end{abstract}

Keywords: Statistical Analysis; Interpretative Analysis; SEM, Readiness and IT Adoption Questionnaire

\section{Introduction}

The era of globalization has demanded that all information be accessed quickly and practically. With the design of a good information system, quality information will be obtained so that relationships between customers and suppliers can be created and can provide added value to the development of SMEs [1]. Information and communication technology that continues to grow influences in almost all fields of life including in the field of education [2], services and social media [3] and SMEs [4, 5]

At present, the management of a company cannot be denied anymore by using and utilizing information technology (IT), including SMEs [5, 6]. In addition to the increasingly competitive level of business competition, 
the need for efficiency and effectiveness in the management of the company itself requires each company to be ready and adopt the use of these technologies. The development of the company in this case, small and medium enterprises SMEs must be encouraged to follow and take technological developments

In the use of information technology fundamentally will bring significant benefits to every user who uses it, but this must be proven firsthand in its development success [7, 8]. And this means that success in the use of information technology will be the first challenge for users before they get the benefits. Another case if the use of information technology is a failure, it will be financially detrimental and will affect the continuity of the operations of the business itself [9].

The purpose of this study was to assess the psychometric properties of the readiness and IT adoption questionnaire and to understand the instrument, in regard to responsiveness and cognition of the respondents. The assessments based on the respondent's perceptions and the exploration using points of view of the researchers were the objectives. Two research questions were then proposed for guiding implementation of the study.

RQ1. Does the readiness and IT adoption questionnaire have a good psychometric property?

RQ2. Does the readiness questionnaire present the responsiveness and cognition of the respondents?

This paper is organized into five sections that will explain the main points of the section. The introductory section will explain the background of the selection of the title, problem statement, the purpose of writing the paper, questions and research hypotheses. The literature review section illustrates theories that support research related to model development. The third part explains the methodological aspects of this research so that it can be used as a reference in subsequent writing. The results and data analysis section will explain the results of the analysis phase, discussion, limitations, and suggestions for future research. And finally, from this writing, there is a conclusion that will later be used as a reference.

\section{Method}

In this study, the researcher developed technology readiness and IT adoption (TRIA) model (Fig.1) by adopting the technology readiness model parasuraman $[10,11]$ and e-business or IT adoption model Zhu [12, 13], combining both models. The technology readiness model consists of 4 variables comprising optimism [OPT], Innovativeness [INV], Discomfort [DSC] and Insecurity [ISC]. The variables of this model will be combined with the adaptation of the adoption model which consists of 6 variables namely Technology Competence [TEC], Firm Scope [FSC], Firm Size [FSZ], Consumer readiness [CRD], Competitive Pressure [CPR], and Lack of trading partner readiness [TPR] and will produce a variable namely IT Adoption [ITA].

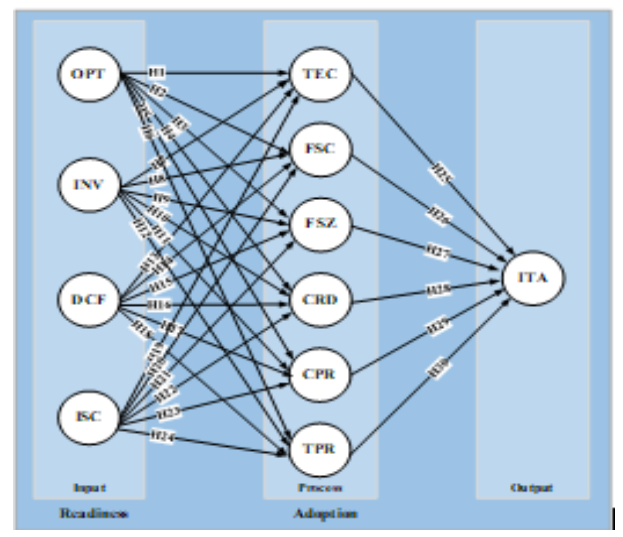

Figure 1. The Developed Model [9]

Table 1. List of the variables [9, 14]

\begin{tabular}{lll}
\hline Codes & Names & Definitions \\
\hline OPT & Optimism & $\begin{array}{l}\text { The level of confidence in believing that technology adoption } \\
\text { might occur. } \\
\text { The level of confidence in seeing that adoption technology is } \\
\text { part of a system. }\end{array}$
\end{tabular}




\begin{tabular}{|c|c|c|}
\hline Codes & Names & Definitions \\
\hline DCF & Discomfort & $\begin{array}{l}\text { The level of confidence in knowing that technology is } \\
\text { uncomfortable. }\end{array}$ \\
\hline ISC & Insecurity & $\begin{array}{l}\text { The level of confidence of distrust that technology adoption } \\
\text { can be properly implemented and concerns about potentially } \\
\text { harmful consequences }\end{array}$ \\
\hline TEC & $\begin{array}{l}\text { Technology } \\
\text { Competence }\end{array}$ & $\begin{array}{l}\text { The level of confidence of technologies (hardware) that enable } \\
\text { an organization to develop processes }\end{array}$ \\
\hline FSC & Firm Scope & $\begin{array}{l}\text { The level of confidence of horizontal expansion of an } \\
\text { enterprise's operations }\end{array}$ \\
\hline FSZ & Firm Size & $\begin{array}{l}\text { The level confidence of which to a larger company may have } \\
\text { a competitive advantage over its smaller counterparts }\end{array}$ \\
\hline CRD & Customer Readiness & $\begin{array}{l}\text { The level of confidence of a combination of consumer } \\
\text { willingness and Internet penetration }\end{array}$ \\
\hline CPR & Competitive Pressure & $\begin{array}{l}\text { The level of confidence to affect the industry structure, and } \\
\text { leverage new ways to outperform rivals, thus changing the } \\
\text { competitive environment }\end{array}$ \\
\hline TPR & $\begin{array}{l}\text { Lack of Trading Partner } \\
\text { Readiness }\end{array}$ & $\begin{array}{l}\text { The level confidence of status of its trading partners along the } \\
\text { value chain, since for an electronic trade to take place, it is } \\
\text { necessary that all trading partners adopt compatible electronic } \\
\text { trading systems }\end{array}$ \\
\hline ITA & IT Adoption & $\begin{array}{l}\text { The level of confidence to which a company adopts a } \\
\text { technology for the development of its industry }\end{array}$ \\
\hline
\end{tabular}

This study also uses the assumption of the logic model input Process Logic (IPO Logic) [15] which is adapted for the same purpose in measuring the quality of a system. Based on the research methodology that was developed, there are 4 stages of the process that will be passed. Starting from the initial concept in the form of design preparation and ending with reports writing. The second and third stages are the most important stages of this research, namely data collection and data analysis. In collecting data, the researcher collected 29 respondents who distributed the questionnaire directly to find out the shortcomings of the questions and statements on the questionnaire sheet. In addition, researchers also got 25 respondents whose questionnaires were distributed through the Google form application.

In processing data, researchers used the MS Excel 2013 application and used the partial least square SmartPLS 2.0 application to be able to display reliability indicators, internal consistency reliability, convergent validity, and discriminant validity assessment [16-20]

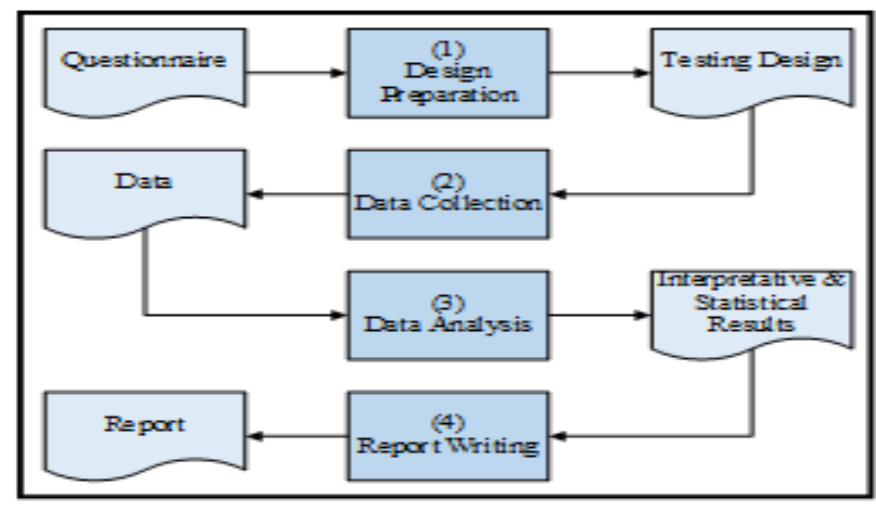

Figure 2. The Research Methodology

The results of calculations carried out will be used as input references for interpretative assessment. Also, there is also information from the respondents' demographics as well as aspects of the respondents that can be taken into consideration in the analysis phase in interpretive assessment. The statistical results and interpretative analysis then make confirmation references which, after going through the analysis process, will be used as findings and recommendation. 


\section{Findings and Discussion}

On table 3 below explained four characteristic respondent's demographics, i.e., gender, education, readiness level for IT use, and readiness factor influences IT usage

Table 3. Respondent's demographics

\begin{tabular}{|c|c|c|c|}
\hline Characteristic & Group & $\mathrm{n}$ & $\%$ \\
\hline \multirow{3}{*}{ Gender } & Male & 37 & 68.5 \\
\hline & Female & 17 & 31.5 \\
\hline & High School & 25 & 46.3 \\
\hline \multirow{4}{*}{ Education } & Diploma & 5 & 9.3 \\
\hline & Bachelor & 22 & 40.7 \\
\hline & Master & 2 & 3.7 \\
\hline & Strongly Ready & 7 & 13.0 \\
\hline \multirow{3}{*}{$\begin{array}{l}\text { Readiness level } \\
\text { for IT Use }\end{array}$} & Ready & 13 & 24.1 \\
\hline & Unready & 33 & 61.1 \\
\hline & Strongly unready & 1 & 1.9 \\
\hline \multirow{5}{*}{$\begin{array}{l}\text { Readiness } \\
\text { Factor } \\
\text { Influences } \\
\text { Usage }\end{array}$} & Strongly Influential & 20 & 37.0 \\
\hline & Influential & 26 & 48.1 \\
\hline & Less Influential & 4 & 7.4 \\
\hline & Uninfluential & 2 & 3.7 \\
\hline & Strongly Influential & 2 & 3.7 \\
\hline
\end{tabular}

In this study, questionnaires were only carried out in the Jakarta and surrounding areas, but the data of this study included the desired SME area. The consistency of the data used is also undoubtedly given the data on SME data used as respondents are the majority of SMEs that are ready for IT use.

The method most often used by researchers in the field of SEM to measure the model through confirmatory factor analysis is to use the MultiTrait-MultiMethod approach by testing convergent and discriminant validity [21]. The sample in this study refers to and considers aspects of key informant. Some researchers have previously explained that the selection of respondents with the right characteristics directly influence the research input data [22-24]. This is related to the trust and correctness of the right data source.

Based on the statistical examinations, the results show that 13 of the 55 indicators were rejected (Table 4).

- The indicator reliability assessment, it is found that there are three of the 55 indicators (i.e., OPT3, DCF4 and ISC 4) are rejected because of the values unfulfilled the requirements of loading factors, namely 0.6 - $0.7[16-19,25]$

- $\quad$ The consistency reliability, it is found the reliability composite (CR) of eleven variables are above 0.7

- $\quad$ The examining convergent validity, the value of Average Variance Extracted (AVE) of eleven variables is greater than the threshold value of 0.5

- The discriminant validity assessment, there are ten indicators (i.e., OPT1, INV3, INV4, DCF2, DCF5, ISC5, FSC5, FSZ1, FSZ3, and FSZ4) which must also be deleted according to Fornell and Lacker rules [31-35], namely, cross loading above 0.7

Table 4. The statistical analysis results

\begin{tabular}{|c|c|c|c|c|c|c|c|c|c|c|c|c|c|}
\hline \multirow{2}{*}{ Var } & \multirow{2}{*}{ Indic } & \multirow{2}{*}{$\mathrm{OL}$} & \multicolumn{11}{|c|}{$\mathrm{CL}$} \\
\hline & & & OPT & INV & DCF & ISC & TEC & FSC & FSZ & CRD & CPR & TPR & ITA \\
\hline \multirow{5}{*}{ OPT } & OPT1 & \multicolumn{12}{|c|}{ Rejected } \\
\hline & OPT2 & 0.86 & 0.87 & 0.41 & 0.10 & -0.01 & 0.65 & 0.58 & 0.45 & 0.42 & 0.56 & 0.47 & 0.59 \\
\hline & OPT3 & \multicolumn{12}{|c|}{ Rejected } \\
\hline & OPT4 & 0.86 & 0.86 & 0.39 & 0.04 & -0.07 & 0.61 & 0.59 & 0.39 & 0.43 & 0.51 & 0.52 & 0.52 \\
\hline & OPT5 & 0.78 & 0.78 & 0.58 & 0.14 & 0.13 & 0.64 & 0.57 & 0.42 & 0.51 & 0.52 & 0.36 & 0.53 \\
\hline INV & INV1 & 0.87 & 0.55 & 0.86 & 0.16 & 0.09 & 0.49 & 0.47 & 0.37 & 0.45 & 0.36 & 0.41 & 0.44 \\
\hline
\end{tabular}




\begin{tabular}{|c|c|c|c|c|c|c|c|c|c|c|c|c|c|}
\hline \multirow{2}{*}{ Var } & \multirow{2}{*}{ Indic } & \multirow{2}{*}{$\mathrm{OL}$} & \multicolumn{11}{|c|}{ CL } \\
\hline & & & OPT & INV & DCF & ISC & TEC & FSC & FSZ & CRD & CPR & TPR & ITA \\
\hline & INV2 & 0.87 & 0.55 & 0.87 & 0.16 & 0.09 & 0.49 & 0.47 & 0.37 & 0.45 & 0.36 & 0.41 & 0.54 \\
\hline & INV3 & \multicolumn{12}{|c|}{ Rejected } \\
\hline & INV4 & \multicolumn{12}{|c|}{ Rejected } \\
\hline & INV5 & 0.85 & 0.46 & 0.85 & 0.19 & 0.20 & 0.29 & 0.43 & 0.53 & 0.32 & 0.24 & 0.48 & 0.3 \\
\hline & DCF1 & 0.88 & 0.15 & 0.16 & 0.88 & 0.36 & 0.15 & 0.24 & 0.31 & 0.11 & 0.09 & 0.20 & 0.18 \\
\hline \multirow{4}{*}{ DCF } & DCF2 & \multicolumn{12}{|c|}{ Rejected } \\
\hline & DCF3 & 0.91 & 0.15 & 0.10 & 0.91 & 0.13 & 0.13 & 0.31 & 0.35 & 0.19 & 0.04 & 0.03 & 0.25 \\
\hline & DCF4 & \multicolumn{12}{|c|}{ Rejected } \\
\hline & DCF5 & \multicolumn{12}{|c|}{ Rejected } \\
\hline \multirow{5}{*}{ ISC } & ISC1 & 0.92 & 0.06 & 0.21 & 0.18 & 0.91 & 0.1 & 0.12 & 0.28 & 0.16 & 0.15 & 0.16 & 0.11 \\
\hline & ISC2 & 0.82 & 0.03 & 0.09 & 0.30 & 0.82 & 0.05 & 0.12 & 0.12 & 0.07 & 0.04 & 0.08 & 0.05 \\
\hline & ISC3 & 0.93 & 0.01 & 0.04 & 0.24 & 0.93 & 0.12 & 0.16 & 0.30 & 0.18 & 0.20 & 0.16 & 0.14 \\
\hline & ISC4 & \multicolumn{12}{|c|}{ Rejected } \\
\hline & ISC5 & \multicolumn{12}{|c|}{ Rejected } \\
\hline \multirow{5}{*}{ TEC } & TEC1 & 0.82 & 0.53 & 0.28 & 0.27 & 0.01 & 0.81 & 0.50 & 0.51 & 0.49 & 0.58 & 0.62 & 0.67 \\
\hline & TEC2 & 0.89 & 0.63 & 0.46 & 0.04 & 0.22 & 0.89 & 0.65 & 0.56 & 0.59 & 0.68 & 0.53 & 0.69 \\
\hline & TEC3 & 0.89 & 0.61 & 0.51 & 0.13 & 0.12 & 0.88 & 0.64 & 0.51 & 0.51 & 0.57 & 0.48 & 0.57 \\
\hline & TEC4 & 0.71 & 0.54 & 0.31 & 0.23 & -0.04 & 0.70 & 0.43 & 0.38 & 0.38 & 0.49 & 0.51 & 0.48 \\
\hline & TEC5 & 0.87 & 0.68 & 0.45 & 0.08 & 0.17 & 0.86 & 0.72 & 0.57 & 0.46 & 0.64 & 0.60 & 0.57 \\
\hline \multirow{5}{*}{ FSC } & FSC1 & 0.80 & 0.70 & 0.52 & 0.26 & 0.22 & 0.75 & 0.80 & 0.59 & 0.51 & 0.52 & 0.58 & 0.57 \\
\hline & FSC2 & 0.71 & 0.59 & 0.48 & 0.18 & 0.07 & 0.64 & 0.71 & 0.46 & 0.62 & 0.59 & 0.62 & 0.64 \\
\hline & FSC3 & 0.87 & 0.49 & 0.34 & 0.30 & 0.12 & 0.43 & 0.87 & 0.73 & 0.62 & 0.49 & 0.60 & 0.50 \\
\hline & FSC4 & 0.87 & 0.49 & 0.34 & 0.30 & 0.12 & 0.43 & 0.87 & 0.73 & 0.62 & 0.49 & 0.60 & 0.50 \\
\hline & FSC5 & \multicolumn{12}{|c|}{ Rejected } \\
\hline \multirow{5}{*}{ FSZ } & FSZ1 & \multicolumn{12}{|c|}{ Rejected } \\
\hline & FSZ2 & 0.83 & 0.62 & 0.42 & 0.26 & 0.14 & 0.63 & 0.77 & 0.82 & 0.69 & 0.73 & 0.70 & 0.72 \\
\hline & FSZ3 & \multicolumn{12}{|c|}{ Rejected } \\
\hline & FSZ4 & \multicolumn{12}{|c|}{ Rejected } \\
\hline & FSZ5 & 0.73 & 0.35 & 0.34 & 0.41 & 0.18 & 0.45 & 0.50 & 0.73 & 0.44 & 0.38 & 0.65 & 0.53 \\
\hline \multirow{5}{*}{ CRD } & CRD1 & 0.85 & 0.66 & 0.48 & 0.04 & 0.24 & 0.64 & 0.77 & 0.68 & 0.85 & 0.78 & 0.59 & 0.61 \\
\hline & CRD2 & 0.84 & 0.35 & 0.26 & 0.22 & 0.24 & 0.4 & 0.50 & 0.52 & 0.84 & 0.74 & 0.40 & 0.39 \\
\hline & CRD3 & 0.73 & 0.38 & 0.34 & 0.16 & -0.01 & 0.48 & 0.52 & 0.47 & 0.72 & 0.54 & 0.47 & 0.41 \\
\hline & CRD4 & 0.80 & 0.29 & 0.48 & 0.20 & -0.05 & 0.33 & 0.55 & 0.58 & 0.80 & 0.60 & 0.59 & 0.47 \\
\hline & CRD5 & 0.85 & 0.45 & 0.25 & 0.23 & 0.22 & 0.44 & 0.58 & 0.68 & 0.84 & 0.69 & 0.55 & 0.45 \\
\hline & CPR1 & 0.78 & 0.48 & 0.31 & 0.12 & 0.06 & 0.65 & 0.57 & 0.58 & 0.70 & 0.77 & 0.64 & 0.58 \\
\hline & CPR2 & 0.92 & 0.54 & 0.32 & 0.05 & 0.22 & 0.71 & 0.55 & 0.59 & 0.72 & 0.92 & 0.61 & 0.61 \\
\hline CPR & CPR3 & 0.85 & 0.47 & 0.24 & 0.12 & 0.07 & 0.52 & 0.55 & 0.59 & 0.72 & 0.85 & 0.48 & 0.57 \\
\hline & CPR4 & 0.87 & 0.53 & 0.36 & 0.06 & 0.15 & 0.58 & 0.50 & 0.53 & 0.74 & 0.86 & 0.49 & 0.53 \\
\hline & CPR5 & 0.76 & 0.51 & 0.40 & 0.06 & 0.15 & 0.51 & 0.52 & 0.58 & 0.59 & 0.75 & 0.60 & 0.62 \\
\hline TPR & TPR1 & 0.86 & 0.49 & 0.52 & 0.32 & 0.03 & 0.66 & 0.71 & 0.67 & 0.59 & 0.59 & 0.86 & 0.69 \\
\hline
\end{tabular}




\begin{tabular}{|c|c|c|c|c|c|c|c|c|c|c|c|c|c|}
\hline \multirow{2}{*}{ Var } & \multirow{2}{*}{ Indic } & \multirow{2}{*}{ OL } & \multicolumn{11}{|c|}{ CL } \\
\hline & & & OPT & INV & DCF & ISC & TEC & FSC & FSZ & CRD & CPR & TPR & ITA \\
\hline \multirow{9}{*}{ ITA } & TPR2 & 0.77 & 0.41 & 0.42 & 0.18 & 0.16 & 0.45 & 0.61 & 0.68 & 0.42 & 0.45 & 0.77 & 0.5 \\
\hline & TPR3 & 0.82 & 0.50 & 0.40 & 0.23 & 0.25 & 0.58 & 0.66 & 0.64 & 0.60 & 0.64 & 0.81 & 0.77 \\
\hline & TPR4 & 0.74 & 0.36 & 0.25 & 0.16 & 0.03 & 0.49 & 0.37 & 0.42 & 0.46 & 0.52 & 0.74 & 0.49 \\
\hline & TPR5 & 0.73 & 0.29 & 0.35 & 0.16 & 0.14 & 0.34 & 0.53 & 0.56 & 0.41 & 0.41 & 0.73 & 0.45 \\
\hline & ITA1 & 0.86 & 0.59 & 0.40 & 0.13 & 0.07 & 0.68 & 0.65 & 0.66 & 0.66 & 0.70 & 0.76 & 0.86 \\
\hline & ITA2 & 0.87 & 0.51 & 0.40 & 0.25 & 0.22 & 0.65 & 0.60 & 0.48 & 0.45 & 0.59 & 0.61 & 0.86 \\
\hline & ITA3 & 0.85 & 0.45 & 0.29 & 0.18 & 0.14 & 0.54 & 0.49 & 0.39 & 0.34 & 0.48 & 0.53 & 0.85 \\
\hline & ITA4 & 0.84 & 0.44 & 0.42 & 0.32 & 0.16 & 0.62 & 0.58 & 0.54 & 0.53 & 0.55 & 0.62 & 0.83 \\
\hline & ITA5 & 0.87 & 0.55 & 0.32 & 0.18 & -0.01 & 0.59 & 0.56 & 0.52 & 0.51 & 0.64 & 0.71 & 0.87 \\
\hline
\end{tabular}

The above statistical results are used to initiate interpretative evaluations by considering the response and cognition of the sample from the respondents' demographics. Briefly, the results of a relative interpretative evaluation confirm the results of statistical.

Indicators OPT1, OPT3, INV3, and INV4 are contributors/positives as well as DCF2, DCF4, DCF5, ISC4 and ISC5 indicators are inhibitors/negatives in the readiness variable. In this study, the nine indicators were rejected. The researcher assumed that the rejection might be related to the respondent's focus when the questionnaire was filled out. Also, the rejection of the nine indicators was due to demographic limitations when the questionnaire was distributed.

Indicators FSC5, FSZ1, FSZ3, and FSZ4 are indicators related to IT adoption where these indicators indicate indicators that are not accepted. This, according to researchers, is most likely due to a lack of understanding of the respondents in answering questions or statements from the questionnaire so that the boundary values that must be accepted are not achieved.

Although of the 55 indicators there are 13 that must be rejected and review the question, the measurement model of the proposed Readiness and IT Adoption model can be justified in statistical calculations as a model that has psychometric properties based on the value obtained [16, 17, 25]. However, the assessment is still based on the reference of the survey instrument used, so that it will be reviewed and try to improve the instrument developed in terms of further testing. From the results of the statistical analysis that has been done using SmartPLS2, it is found that reliability and validity of indicators can be known. Based on these results, an interpretative evaluation is carried out concerning statistical analysis.

\section{Conclusion}

From the research objectives to be achieved is assessing the psychometric nature of users, in this case, the readiness of SMEs in adopting information technology. The questions developed on the questionnaire in this study greatly influence the results of the psychometric traits to be achieved. The development of surveys and statements and questionnaire questions based on adoption, combination, and adaptation were very influential in this study. The demographics of the respondents also greatly influence the results of the study, so there are several factors that might be considered in the next study, namely the condition of the respondents when filling out the survey provided.

In this study, psychometric and sequential implementation interpretative assessment is carried out to examine and explore the validity and reliability of the questionnaire. And the results showed that 13 of the 70 questions in the questionnaire were recommended for rejection. In addition to the results of the psychometric and interpretative analysis, it is produced the conclusion presentation can also be the second point highlighted in this study.

This study also limits its use according to the sample used when distributing questionnaires. The technique and questionnaire development model are the results of the creation and interpretative of the researcher in the preparation of the questionnaire.

Further research will be developed in the questionnaire, so that when a pilot study is conducted it will get better and more accurate results. The results of the pilot study will provide a detailed description of all the conditions in this study 


\section{REFERENCES}

[1] B. Ritchie and C. Brindley, "ICT adoption by SMEs: implications for relationships and management," New Technology, Work and Employment, vol. 20, no. 3, pp. 205-217, 2005.

[2] A. Subiyakto, A. R. Ahlan, M. Kartiwi, S. J. Putra, and Y. Durachman, "The User Satisfaction Perspectives of the Information System Projects," Indonesian Journal of Electrical Engineering and Computer Science, vol. 4, no. 1, 2016.

[3] M. I. Dahnil, K. M. Marzuki, J. Langgat, and N. F. Fabeil, "Factors influencing SMEs adoption of social media marketing," Procedia-social and behavioral sciences, vol. 148, pp. 119-126, 2014.

[4] A. Buchalcevova, "Green ICT maturity model for Czech SMEs," Journal of Systems Integration, vol. 6, no. 1, pp. 24-36, 2015.

[5] A. Tarutè and R. Gatautis, "ICT impact on SMEs performance," Procedia-Social and Behavioral Sciences, vol. 110, no. 0, pp. 1218-1225, 2014.

[6] D. Consoli, "Literature analysis on determinant factors and the impact of ICT in SMEs," Procedia-social and behavioral sciences, vol. 62, pp. 93-97, 2012.

[7] S. H. Doong and S.-C. Ho, "The impact of ICT development on the global digital divide," Electronic Commerce Research and Applications, vol. 11, no. 5, pp. 518-533, 2012.

[8] N. Marangunić and A. Granić, "Technology acceptance model: a literature review from 1986 to 2013," Universal Access in the Information Society, journal article vol. 14, no. 1, pp. 81-95, March 012015.

[9] A. Sani, A. Subiyakto, and T. K. A. Rahman, Integration of the Technology Readiness and Adoption Models for Assessing IT Use among SMEs in Indonesia. 2018.

[10] A. Parasuraman and C. L. Colby, "An updated and streamlined technology readiness index: TRI 2.0," Journal of service research, vol. 18, no. 1, pp. 59-74, 2015.

[11] A. Parasuraman, "Technology Readiness Index (TRI) a multiple-item scale to measure readiness to embrace new technologies," Journal of service research, vol. 2, no. 4, pp. 307-320, 2000.

[12] K. Zhu, K. Kraemer, and S. Xu, "Electronic business adoption by European firms: a cross-country assessment of the facilitators and inhibitors," European Journal of Information Systems, vol. 12, no. 4, pp. 251-268, 2003.

[13] P. Chatzoglou and D. Chatzoudes, "Factors affecting e-business adoption in SMEs: an empirical research," Journal of Enterprise Information Management, vol. 29, no. 3, pp. 327-358, 2016.

[14] A. Subiyakto, "Development of The Readiness and Success Model for Assessing the Information System Integration," presented at the International Conference on Science and Technology (ICOSAT) 2017, Jakarta, 08 October 20172017.

[15] W. S. Davis and D. C. Yen, The Information System Consultant's Handbook: Systems Analysis and Design. CRC press, 1998.

[16] J. F. Hair Jr, G. T. M. Hult, C. Ringle, and M. Sarstedt, A primer on partial least squares structural equation modeling (PLS-SEM). Sage Publications, 2016.

[17] J. F. Hair, C. M. Ringle, and M. Sarstedt, "PLS-SEM: Indeed a silver bullet," Journal of Marketing theory and Practice, vol. 19, no. 2, pp. 139-152, 2011.

[18] K. K.-K. Wong, "Partial least squares structural equation modeling (PLS-SEM) techniques using SmartPLS," Marketing Bulletin, vol. 24, no. 1, pp. 1-32, 2013.

[19] J. Willy Abdillah, "Partial Least Square (PLS), Alternatif SEM," (in Indonesia), vol. 1, p. 262, 2015.

[20] W. Afthanorhan, "A comparison of partial least square structural equation modeling (PLS-SEM) and covariance based structural equation modeling (CB-SEM) for confirmatory factor analysis," International Journal Engineering and Science Innovative Technologies (IJESIT), vol. 2, no. 5, p. 8, 2013. 
[21] D. T. Campbell and D. W. Fiske, "Convergent and discriminant validation by the multitraitmultimethod matrix," Psychological bulletin, vol. 56, no. 2, p. 81, 1959.

[22] A. Subiyakto, A. R. Ahlan, M. Kartiwi, and S. J. Putra, "Measurement of the information system project success of the higher education institutions in Indonesia: a pilot study," International Journal of Business Information System, vol. 23, no. 2, pp. 229-247, 2016.

[23] S. M. Frenk, S. L. Anderson, M. Chaves, and N. Martin, "Assessing the validity of key informant reports about congregations' social composition," Sociology of Religion, vol. 72, no. 1, pp. 7890, 2011.

[24] A. Yazdani et al., "Key Informants' Perspectives: Management Commitment, Training, and Worker Participation in the Prevention of Musculoskeletal Disorders," IISE Transactions on Occupational Ergonomics and Human Factors, no. just-accepted, pp. 00-00, 2017.

[25] J. F. Hair, M. Sarstedt, C. M. Ringle, and J. A. Mena, "An assessment of the use of partial least squares structural equation modeling in marketing research," Journal of the academy of marketing science, vol. 40, no. 3, pp. 414-433, 2012. 